\section{Upper limits of intraocular pressure in glaucoma clinical trials}

The parallel, randomized, double-masked, activecontrolled trial is generally thought to be the most rigorous and unbiased design to adequately compare two glaucoma medicines. ${ }^{1,2}$ Important to this design is the intraocular pressure entry criteria. The lower limit of intraocular pressure is usually set at least $>21 \mathrm{mmHg}$ to help assure the study population has the appropriate diagnosis (ocular hypertension or primary open-angle glaucoma). ${ }^{1,2}$

In contrast, an upper limit intraocular pressure may be set in the entry criteria for safety reasons to help assure that any subject randomized would experience a sufficient decrease in intraocular pressure to control their glaucoma throughout the clinical trial. However, little data are available that examines the impact of an upper limit on the intraocular pressure results of clinical trials.

The purpose of this study was to review past parallel, randomized, active-controlled, single- or double-masked monotherapy glaucoma trials to determine the association of the upper limit of intraocular pressure specified in the entry criteria to baseline and active treatment intraocular pressures.

Articles evaluated in this analysis were dated from January 1995 to April 2011 and found on PubMed (http://www.pubmed.gov) using the following search terms: primary open-angle glaucoma, ocular hypertension, intraocular pressure, diurnal, monotherapy, baseline, reduction, beta-blockers (timolol, timolol gelforming solution, betaxolol, carteolol, levobunolol), carbonic anhydrase inhibitors (dorzolamide, brinzolamide), alpha-agonists (brimonidine, brimonidine preserved with polyquaternium-1, brimonidine preserved with chlorine dioxide, apraclonidine), prostaglandins (latanoprost, travoprost, bimatoprost) and combination therapy (brinzolamide/timolol, dorzolamide/timolol, latanoprost/timolol, travoprost/timolol, brimonidine/ timolol, bimatoprost/timolol). Brand names of single and fixed combination agents were also used as search terms.

Complete articles were retrieved and studies were accepted into the database if they were randomized, prospective, parallel, single- or double-masked, activecontrolled, monotherapy trials with at least 60 patients per treatment arm and with 6 weeks of treatment. Only subjects with ocular hypertension or primary open-angle glaucoma were included. Studies with exfoliation and pigment dispersion glaucoma patients were included if they each comprised $<10 \%$ of the total patient sample size. Studies must have had both baseline and treated diurnal intraocular pressure measurements consisting of at least three time points. Intraocular pressures must have been measured with Goldmann applanation tonometry.

PRN Pharmaceutical Research Network, LLC analyzed the data. The level to declare significance was .05 and all

Competing/conflicts of interest: No stated conflict of interest.

Funding sources: No stated funding sources. analyses were two way. Mean intraocular pressure values for the morning intraocular pressure and diurnal pressures were analyzed between analyses methods by a one-way analysis of variance test. ${ }^{3}$ Because of multiple comparisons, we used a modified Bonferroni correction $(\alpha / 2)$.

This study included 37 treatment arms from 22 studies, of which 20 treatment arms were prostaglandin-related compounds and 17 beta-blockers. Citations for the 22 studies can be found online (Supporting Information, Text S1). The other classes of medicines did not have sufficient treatment arms to provide a valuable comparison.

The results are shown in Table 1 and reveal, following a modified Bonferroni correction, at baseline the upper limit entry pressures of $34,36 \mathrm{~mm} \mathrm{Hg}$ or no upper limit for prostaglandins; and upper limit entry pressures of $30,34,36 \mathrm{mmHg}$ or no upper limit for beta-blockers were statistically different for the morning and diurnal intraocular pressures for both medicine classes $(P \leq 0.01)$. Further, the pressures at the active treatment visit were statistically different across groups for prostaglandins for the morning $(P=0.004)$ and diurnal pressures $(P=0.01)$.

In contrast, the active treatment visits for the morning $(P=0.67)$ and diurnal intraocular pressures $(P=0.38)$ were statistically similar for beta-blockers. Furthermore, the intraocular pressure reduction from untreated baseline for the morning and diurnal intraocular pressures for both the prostaglandin and beta-blocker groups was not statistically different across all three upper intraocular pressure limits $(P \geq 0.06)$.

This study showed that the upper limit for the intraocular pressure as an entry criterion may affect both the baseline and active treatment visit intraocular pressures. For prostaglandins, a requirement of 34 or $36 \mathrm{mmHg}$ or no limit showed a statistical difference for the morning and diurnal baseline intraocular pressures. Also a difference was observed with beta-blockers between 30, 34 or $36 \mathrm{mmHg}$ or no upper limit at both morning and diurnal baseline intraocular pressures. This difference makes sense as patients with higher untreated intraocular pressures at baseline admitted to a clinical trial, should demonstrate a resultant higher mean baseline intraocular pressure. However, to our knowledge, this has not been previously shown. Interestingly, studies with no upper limit of entry criteria intraocular pressure failed to provide a higher mean intraocular pressure than those with a limit of $36 \mathrm{mmHg}$ for both prostaglandins and beta-blockers. The reason for this is not known.

The reason for using an upper limit of intraocular pressure in clinical trials usually is for safety reasons to prevent enrolment of a patient with such high intraocular pressures that, even with treatment, would risk glaucomatous progression during the study. An even lower upper limit entry intraocular pressure might be required in studies when a placebo is used as the control, or if only one eye is treated leaving the contralateral eye untreated.

However, a higher upper limit entry intraocular pressure may be desirable, in appropriate designs, to provide a higher mean baseline intraocular pressure. It has been shown that the higher the mean baseline intraocular 
Table 1. Prostaglandin and beta-blocker intraocular pressures $(\mathrm{mmHg})$

\begin{tabular}{|c|c|c|c|c|c|c|c|c|c|}
\hline \multirow{2}{*}{$\begin{array}{l}\text { Upper limit } \\
\text { Prostaglandir }\end{array}$} & \multirow[t]{2}{*}{ Arms } & \multirow[t]{2}{*}{$\begin{array}{l}\text { Baseline } \\
\text { morning }\end{array}$} & \multirow[t]{2}{*}{$\begin{array}{l}\text { Baseline } \\
\text { diurnal }\end{array}$} & \multirow[t]{2}{*}{$\begin{array}{c}\text { ATV } \\
\text { morning }\end{array}$} & \multirow[t]{2}{*}{$\begin{array}{c}\text { ATV } \\
\text { diurnal }\end{array}$} & \multicolumn{2}{|c|}{$\begin{array}{l}\text { Morning reduction } \\
(\mathrm{mmHg} / \%)\end{array}$} & \multicolumn{2}{|c|}{$\begin{array}{c}\text { Diurnal reduction } \\
(\mathrm{mmHg} / \%)\end{array}$} \\
\hline & & & & & & & & & \\
\hline $34 \mathrm{mmHg}$ & 3 & $25.0 \pm 0.8$ & $23.3 \pm 0.5$ & $17.9 \pm 0.7$ & $17.2 \pm 0.5$ & $7.1 \pm 1.4$ & 28 & $6.1 \pm 0.9$ & 26 \\
\hline $36 \mathrm{mmHg}$ & 7 & $27.4 \pm 1.0$ & $26.2 \pm 0.9$ & $19.4 \pm 0.7$ & $18.6 \pm 0.6$ & $8.0 \pm 0.8$ & 29 & $7.6 \pm 0.7$ & 29 \\
\hline None & 10 & $25.9 \pm 0.7$ & $24.6 \pm 1.1$ & $17.8 \pm 1.0$ & $17.3 \pm 0.9$ & $8.1 \pm 1.0$ & 31 & $7.2 \pm 0.9$ & 29 \\
\hline$P$ values & & 0.0007 & 0.002 & 0.004 & 0.01 & 0.29 & & 0.06 & \\
\hline \multicolumn{10}{|c|}{ Beta-blockers } \\
\hline $30 \mathrm{mmHg}$ & 2 & $24.4 \pm 0.3$ & $23.6 \pm 0.1$ & $19.1 \pm 1.3$ & $18.2 \pm 0.7$ & $5.3 \pm 1.0$ & 21 & $5.4 \pm 0.6$ & 23 \\
\hline $34 \mathrm{mmHg}$ & 3 & $25.3 \pm 0.5$ & $23.5 \pm 0.3$ & $19.4 \pm 0.3$ & $18.6 \pm 0.4$ & $5.8 \pm 0.4$ & 23 & $4.9 \pm 0.1$ & 21 \\
\hline $36 \mathrm{mmHg}$ & 6 & $27.1 \pm 1.3$ & $25.8 \pm 1.3$ & $20.1 \pm 0.9$ & $19.5 \pm 0.9$ & $7.0 \pm 1.0$ & 26 & $6.4 \pm 1.0$ & 24 \\
\hline None & 6 & $26.5 \pm 0.7$ & $25.3 \pm 0.7$ & $19.6 \pm 1.3$ & $19.2 \pm 1.2$ & $6.8 \pm 1.2$ & 26 & $6.1 \pm 1.2$ & 24 \\
\hline$P$ values & & 0.01 & 0.009 & 0.67 & 0.38 & 0.14 & & 0.20 & \\
\hline
\end{tabular}

ATV, active treatment visit.

pressure, the greater the drop in intraocular pressure that might occur with the active treatment. ${ }^{4}$ Theoretically, with a greater drop in intraocular pressure, any differences between two actives might be exaggerated, and the study would more likely reach the $1.5 \mathrm{mmHg}$ level, which is typically used in clinical trial design to determine a statistical difference in efficacy between treatment groups. However, no study has demonstrated that higher baseline intraocular pressures do indeed help differentiate the efficacy between two treatments with more validity.

At the last active treatment visit, this study showed among prostaglandin treatment arms that a statistical difference among upper limit entry intraocular pressures continued to be observed for the morning and diurnal intraocular pressure measurements. This was not the case with beta-blockers, however. Further, the reductions from baseline were not statistically significant for either prostaglandins or beta-blockers for either the morning or diurnal intraocular pressure measurements among different upper limit entry intraocular pressures. Therefore, this difference between beta-blockers and prostaglandins in treatment intraocular pressures was not confirmed by the lack of difference in reduction of intraocular pressures. Accordingly, it is difficult to determine currently if the differences in treated intraocular pressures for prostaglandins based on the level of untreated baseline intraocular pressures is real or not. This study suggests that differences in the upper limit for entry of intraocular pressure at baseline in well-controlled clinical trials may influence the mean intraocular pressure at baseline.

\section{David L DeMill BA, ${ }^{1}$ Barbara M Wirostko $M D,{ }^{2}$ Lindsay A Nelson $\mathrm{BS}^{3}$ and William C Stewart $\mathrm{MD}^{3}$ \\ ${ }^{1}$ Department of Ophthalmology and Visual Science, University of Michigan, Ann Arbor, Michigan, ${ }^{2}$ Department of Ophthalmology, John A. Moran Eye Center, University of Utah, Salt Lake City, Utah, and ${ }^{3}$ PRN Pharmaceutical Research Network, LLC, Cheyenne, Wyoming, USA Received 23 April 2014; accepted 29 April 2014.}

\section{RefERENCES}

1. Stewart WC. Clinical Practice of Glaucoma. Thorofare, NJ: Slack, Inc., 1990.

2. Shields MB. Textbook of Glaucoma. Baltimore, MD: Williams \& Wilkins, 1996.

3. Book SA. Essentials of Statistics. New York: McGraw-Hill, Inc., 1978.

4. Heijl A, Leske MC, Hyman L, Yang Z, Bengtsson B. Intraocular pressure reduction with a fixed treatment protocol in the Early Manifest Glaucoma Trial. Acta Ophthalmol 2011; 89: 749-54.

\section{SUPPORTING INFORMATION}

Additional Supporting Information may be found in the online version of this article at the publisher's web-site:

Text S1. Articles reviewed.

\section{Glaucoma drainage device exposure in Asian eyes}

The use of glaucoma drainage devices (GDD) has been well established in the treatment of medically refractory glaucoma. ${ }^{1}$ Tube exposure was reported as one of the main late complications. ${ }^{2}$ It increases the risk of endophthalmitis $^{3,4}$ and requires immediate attention. We aim to evaluate the incidence of tube exposure in Asian eyes, and to identify associations with it.

Competing/conflicts of interest: No stated conflict of interest. Funding sources: No stated funding sources. 